\title{
The Emerging Promise of Touchscreen Devices for Individuals with Intellectual Disabilities
}

\author{
Kjartan Skogly Kversøy ${ }^{1}{ }^{(D}$, Ryan O. Kellems ${ }^{2, * \mathbb{D}}$, Abdul-Razak Kuyini Alhassan ${ }^{3}$, \\ Heidi C. Bussey ${ }^{2}$ and Sofie Daae Kversøy ${ }^{4}$ \\ 1 Department of Vocational Teacher Education, Oslo Metropolitan University, 0167 Oslo, Norway; \\ kkversoy@oslomet.no \\ 2 Counseling Psychology and Special Education, Brigham Young University, Provo, UT 84602, USA; \\ hcbussey@gmail.com \\ 3 Department of Educational Science, University of South Eastern Norway, 3035 Drammen, Norway; \\ Abdul-Razak.Alhassan@usn.no \\ 4 Independent Freelance Researcher, 3034 Drammen, Norway; bankofsofie@gmail.com \\ * Correspondence: rkellems@byu.edu; Tel.: +1-801-422-6674
}

Received: 25 June 2020; Accepted: 23 September 2020; Published: 27 September 2020

\begin{abstract}
This article explores the emerging promise touchscreen devices hold for individuals with intellectual disabilities (ID). Many individuals with ID that struggle to read, write or use voice assisted strategies can use touchscreen devices in many aspects of their lives. Research has shown that touchscreen technology is available, easy to use and can open an array of empowering possibilities for individuals with ID. In this article we will be sharing research and a vision for possible uses of touchscreen devices in the future for individuals with ID. Our perspectives are shaped by our experiences with using touchscreen technology in collaboration with people who have ID. A special aspect of our research methodology is the fact that one of our co-researchers has ID.
\end{abstract}

Keywords: touchscreen; disability; intellectual disabilities; ID; autism; ASD; assistive technology; universal design; tablet; smartphone; iPad; iPhone

\section{Introduction}

Touchscreens are frequently used in applications, from automated teller machines (ATMs), to self-service stations in grocery stores and fast food restaurants. Touchscreens are also the most common means of input into mobile phones (e.g., smartphones). The learning curve to use a touchscreen device can seem easy for many, but for those with intellectual disabilities (ID) it can initially seem daunting [1]. ID is characterized by significant limitations in both adaptive behavior and intellectual functioning. However, most people with ID can learn how to use touchscreen devices and eventually will become quite proficient. Many parents and caregivers see the potential for entertainment and learning for their children through touchscreen devices, including, but not limited to, tablets and smartphones. It is common in today's society to see children operating a variety of touchscreen devices on their own in a variety of different settings, from home to school and work. Today children as young as three years old can be seen using touchscreen devices and simple apps. Toddlers are even a target group for many app developers (Example: https://www.verywellfamily.com/best-apps-to-get-for-toddlers-4582650). We are not claiming that toddlers are a group suited for using this technology, but it shows that app developers are targeting groups that most often cannot read, write or use voice assisted technology. Touchscreen devices also show the promise of emerging universal design principles, which can be relevant for people with ID that struggle with reading, writing and using voice assisted technology.

Due to the nature of touchscreen devices, which allow computer access without requiring a keyboard and mouse, they can be useful for people who experience difficulties because of ID. For many 
individuals with ID, the method of human-computer interaction via a mouse or keyboard can present significant extra obstacles, which are not present when using a touchscreen device. This does not mean that all people with ID are able to use touchscreen devices, but it means that touchscreen devices are not in the same way dependent on the user understanding letters and numbers as in the case of using a keyboard. The touchscreen is also more direct in its use, in contrast to using a mouse. For instance, in using a touchscreen device, one simply needs to point and touch directly on the thing on the screen in order to touch and activate. Although there are many interactional methods that can be used on a touchscreen, and some are complicated and difficult, most of the "touch-on-screen" methods are intuitively easier to operate than a keyboard or a mouse.

This article will focus on the potential benefits of using touchscreen devices for people with ID. Specifically, this manuscript will focus on those individuals with ID who struggle to read, write, or use voice assisted technology. For these individuals, touchscreens show great promise as a way of accessing information, entertainment and social experiences. The authors of this article argue that touchscreen devices can also be used for engagement, collaboration, enthusiasm, enhancing meaning and memory, reflection, recognition, and action. The aim of this article is to present a proposition that growth, independence and empowerment can occur through the thoughtful and systematic use of touchscreen devices with and by individuals with ID.

\subsection{Perspectives from an Author with ID}

Our research is to some extent based on the collaboration between the first and the fifth author of this article [2]. This has been a parent/daughter collaboration through many years. The fifth author has severe ID, and is not able to read, write in any practical usable sense, or use voice assisted technology. However, she has been using, and playing and experimenting with, touchscreen devices since 2011. Our research team views her as a co-researcher and not an informant. She has been developing strategies and solutions for ways of using touchscreen devices while the rest of the research group has been engaged in interpreting and understanding.

The Research Council of Norway, in line with the research policies from the European Union (https://ec.europa.eu/research/social-sciences/pdf/policy_reviews/co-creating_eu_citizenship. pdf), is recommending more inclusion, collaboration and active citizenship in research [3]. This opens new questions about having people with ID as co-researchers. However, we discussed our special case with the Norwegian Centre for Research Data. Through our correspondence with them it was made clear that people with ID have the same right to be acknowledged for their contributions to research as everyone else. The fifth author has contributed to two earlier articles published in 2018 [2] and in 2019 [4]. Since the fifth author is 14 years old, it is recommended that the data be presented by one of the parents. Her participation is an example of how active citizen participation " (.. ) may provide a democratic corrective to choices as to what research should focus on and be aimed at" [5]. According to the Norwegian National Research Ethics Committees (NENT): "Researchers must use appropriate methods to ensure that the affected parties are involved. ( ... )".

We recognize there are challenges in preserving objectivity when working as a large research group separated by distance. All the members of the research group have been actively involved in interpreting the data. For example, the third author has, since 2016, been observing the interaction between the fifth author and the touchscreen device directly. The second and fourth author have been analyzing videos from the same interaction.

The fifth author has been using standard touchscreen devices with standard generic apps. All the devices she has been using have been different generations of Apple iPad and iPhone. She also uses these devices at school. The fifth author prefers to develop and learn in her own way and then demonstrate to the rest of the researchers her new solutions and skills. Her interests and curiosity are key to exploration and development. We also try to identify needs and wishes that can be met through her touchscreen device and point her in a potential direction of development and learning. If a new app catches the fifth author's attention, she will tell us that she is interested in acquiring it. 
If the app holds her interest, she develops her skills and strategies through exploring and playing with it. The fifth author has more than $6000 \mathrm{~h}$ of user experience with these devices. She loves princesses, song and dance. Her various interests fuel active searching on YouTube for similar videos which also get her in touch with new and different videos. As a result, the starting point of our research team's methodology was in many ways focused on the fifth author's interests, needs, wants and wishes. Our job was to supply the tools and suggest directions to meet those needs (ibid).

\subsection{Pedagogical and Psychological Elements}

For all individuals, including those with ID, to enhance their performance, there are specific pedagogical and psychological elements that are worth noting. These are both common-sensical and non-controversial. They have been identified by a long tradition of theory and research, including Vygotsky's work which states the following: (1) People need to be recognized for who they are and where they are, (2) an individual's motivation can be a source of power, and (3) the experience of mastery comes through being able to do something and doing it for oneself. This begs for certain pedagogical strategies in facilitating development and learning [6].

First, people with and without ID need to be recognized for who they are and where they are. Vygotsky [6] shows us that development should start from where you are. If we overstretch the proximal zone of development, learning suffers. This is also connected to where we put our learning focus. If we place our main focus on fixing what does not work in a person's life, it results in struggling to find the necessary motivation. In contrast, if we prioritize strengths we can facilitate their development further. If letters, numbers and reading are difficult for an individual and singing and dancing is a joy, then there might be greater potential in using song and dance for development and learning. The fifth author has been struggling to learn letters and numbers at school for nine years with minimal progress. She has struggled to acquire adequate skills for reading or writing. At the same time, she can hold a note, sing the correct melody of a song and do a systematic dance.

Second, there are forces that can be set in motion through utilizing a person's individual motivation. People with ID have needs, interests, wishes, passions, dreams and curiosity. These are sources that can create action. Sources of action can be identified through asking individuals directly and on their behalf: What does the person in question need? What is interesting for that person? What does the person wish for or dream about? What tends to awaken curiosity?

The final element is mastery or skill development. This might seem logical or assumed; however, it is often not taken sufficiently into consideration. You might know where you are, and you might know where you want to go, but getting there is about doing. Even though you might never get where you imagined you would get, every step you take by yourself is something mastered. By combining these three pedagogical and psychological elements, development and independence will build over time.

\section{Literature Review}

Since the passage of the Technology-related assistance for individuals with disabilities act (Tech Act) was passed in the United States in 1988 [7], there has been an increased emphasis on using technology for individuals with disabilities. Technology has become a ubiquitous part of everyday life for billions of people. Technology has been integrated into society to make life easier and more enjoyable. As such, we should expect technology to be utilized in the same manner for individuals with ID to help fully integrate them into society and provide them with the best life possible [7]. We are not saying that a good life depends on the person being able to use touchscreen technology, but to a large degree the world today is filled with these devices. Many methods of social interaction are dependent on participation via touchscreen devices.

Technology has become a near universal part of life, and to fully realize one's quality of life, the ability to access and use technology seems to be critical. This is as true for people with ID as it is for the general public. Technology provides powerful ways to address limitations in functioning and to provide access to environments in which people with ID live, learn, work, or play. Digital 
technology can improve communication, support social interaction, enhance learning tasks and personal independence and increase leisure time in daily life [8]. In fact, the potential for technology to contribute to a better quality of life for people with ID is more than simply convenience; it becomes one of access [9]. Access is defined as the ability of an individual to obtain and utilize a given piece of technology [9]. One example would be that in order to access a smartphone one would need the ability to turn on the device and unlock the device, and the fine motor and cognitive skills to navigate the device via the touchscreen interface. It should be noted that some individuals with ID may not have the requisite fine motor skills or cognitive ability to successfully utilize touchscreen technology.

People with ID have goals and aspirations, and interactive multimodal technology can help to enhance the quality of their life experiences. Society as a whole can also benefit from people with ID who become more independent, as they can rely on technology for assistance with some tasks instead of a parent, sibling or caregiver. As people with ID are being integrated into society in different ways, such as their increased presence in the community and in employment, they have experienced more opportunities and freedoms in many aspects of their lives. Technology plays a critical role in greater autonomy by allowing them to utilize technology for support as opposed to a caregiver [7]. New technologies, such as tablets and smartphones, have been created, enlarging the possibilities for interaction through new multimodal user interfaces and input techniques, including touchscreen devices [10].

Hagarty and Aspinall [11] used qualitative measures to evaluate what those working directly with individuals with ID should do to help individuals with ID access technology. The study revealed that if given proper support, individuals with ID were able to access and use the technology [11]. Research has shown that specific instructional methods, such as backward chaining, where a task is broken down and taught in reverse order, can be an effective method to teach technology skills to people with ID [12].

\subsection{Assistive Technology}

In the last 10 years, the National Center for Technology Innovation (NCTI) in the United States has been following changes in educational and assistive technology (AT), which has shifted to the more portable touchscreen devices widely used by the general population [13]. According to the reauthorization of the Assistive Technology Act [14], an AT device is defined as "any item, piece of equipment, or product system, whether acquired commercially off the shelf, modified, or customized, that is used to increase, maintain or improve the functional capabilities of people with disabilities" [15]. Many devices have embedded off-the-shelf assistive technology, but often the opportunity is lost due to lack of knowledge about these possibilities [16].

Edyburn [17] emphasizes the positive impact technology has on the lives of people with disabilities. Similarly, Blackhurst (ibid) notes that Assistive Technology (AT) enhances, improves and maintains the individual's performance capabilities. This includes (a) activities of daily living, (b) communication, (c) bodily support, (d) protection and positioning, (e) travel and mobility, (f) environmental interaction, and (g) sports, fitness and recreation. As indicated earlier, the touchscreen devices may include any communication devices that include media technologies that enhance or pave the way for a person with ID to " $(\ldots)$ receive or express communication in both oral and written or visual form or to engage in social interactions" (ibid).

Touchscreen devices, while not specifically designed for education or developmental interventions, have already proven to provide therapeutic and educational benefits for individuals with disabilities when used for AT purposes. For example, Williams and Shekhar [1] note that smartphone apps are easier to use compared to other computers using keyboards. AT devices are a critical tool for providing support to individuals with disabilities to access their environment and meet their needs in a wide range of areas [18]. AT devices provide individuals with disabilities more equal access and opportunities. In a meta-analysis of electronic AT devices, the principal finding was that products should be made easier to use and uniquely adopted for the individual user to foster independence [19]. 
In another study, researchers concluded that having the ability to access the internet is a way of improving cognitive abilities, communication and inclusion, even for those with severe disabilities [20].

\subsection{Universal Design}

One of the most important design philosophies for maximizing the widespread use and adoption of technology is universal design (UD). UD is the process of creating products that can be accessed by as many people as possible, with the widest possible range of abilities, operating within the widest possible range of situations [21]. Whereas AT devices have advantages, in that they are designed specifically for people with disabilities, UD involves building products so that they are inherently flexible and usable by everyone, including people with disabilities.

The major advantage of UD is that it costs the consumer nothing extra (they are buying the same product as everyone else) and allows them to have access to the technologies encountered in public places. Universal design avoids the stigma associated with people with disabilities having to use special devices [22]. We experience and argue that there is a stronger motivation for using touchscreen devices that are the same as the ones "everyone else" is using. There is also better potential for interaction by using such devices in a social setting where friends and family are using the same devices and technology. We have even experienced that our fifth author has been able to give instructions in situations where she knows a device and an app better than the person she is interacting with. This is associated with strong feelings of mastering and proudness. There is often potential embarrassment by being different. In this case we see the potential empowerment in being the same and using the same devices. Thomas Hehir [23] argues that "Students with disabilities are unlikely to progress as well in school and in life if they are ashamed of their disability or uncomfortable disclosing it".

Touchscreen devices are often simpler to use and enhance technology access for many, including those with visual impairments, auditory impairments, motor and physical impairments, and cognitive impairments [24]. Similarly, Hitchcock asserted that UD has huge potential: it can change digital content to allow for multiple representations (e.g., image and sound), transform one medium to another (e.g., printed text to digital speech), change characteristics of presentations (e.g., size, color, contrast), and provide the same basic learning content for people at different levels. In every sense, this suggests that UD permits individuals with ID, through touchscreen devices, to choose and apply digitally produced materials (e.g., apps). UD can provide scaffolds for people with ID, enhance communication, potential and skills, and build self-esteem [25]. An example of universal design can be found in the design and implementation of several different widely available technologies. One specific example is the accessibility features included on smartphones. While features such as the ability to use high contrast backgrounds and larger text was designed to assist those with visual impairments, they are also widely used by many individuals without a visual impairment; similar to how ramps in sidewalks are designed for those in wheelchairs, but are also used by people with strollers and children on skateboards. As technology has advanced, so has the incorporation and adoption of universal design principles. Thomas Hehir argues that universal design is promising. It is flourishing and evolving. Its overall goal is to minimize the impact of disability and maximize the opportunities for individuals with disabilities to participate and thrive in all spheres of life [23].

\section{Emerging Areas and Discussion}

There are many emerging areas associated with the potential of touchscreen devices to improve the lives of individuals with ID. The following are some examples of how using touchscreen devices can foster independence in individuals with ID, supported by the experiences of the authors: (1) using touchscreen devices as a tool to build meaning, (2) using touchscreen devices as a tool for learning digital skills, and (3) using touchscreen devices as a means of inclusion and communication. 


\subsection{Using Touchscreen Devices as a Tool to Build Meaning}

Touchscreen devices have the potential to be used as a tool to build meaning for people with ID who struggle with reading, writing and oral language. The potential benefits of using a touchscreen device to build meaning include (1) being able to share experiences with others, (2) adding meaning to daily experiences, and (3) capturing memories, both alone and with others.

An example is how students with ID can share experiences from their school setting. When the fifth author is asked how her day at school was, she will most often answer, "No, no, no." This can be an age-appropriate annoyance to a repeated question from parents; however, due to her lack of expressive language, it is often rather an expression of embarrassment. She knows she does not have enough words and sentences to express an adequate answer. By allowing students with ID to utilize a touchscreen device to record some of their school day through videos and pictures, they can express more of how their school day has been. The teacher, for example, can send a message to the parents and tell something about the school day: "She has been doing yoga at school today and we have filmed it". This opens a new dimension of communication. We can ask, "Your teacher said you had yoga at school today. Can we see?" The fifth author will most often find the relevant video and answer, "You come and see?" In similar ways, parents and teachers can utilize technology to communicate with students, which can provide a richer experience than if they were to rely solely on verbal communication.

\subsubsection{Adding Meaning to Daily Experiences}

Philosophers like Hilary Putnam [26], Donald Davidson [27] and Hans-Georg Gadamer [28] will agree that "meaning" is something that emerges between people through communication as a way of sharing and reflecting. Touchscreen devices allow for more advanced sharing and communication for people with ID who may struggle with verbal forms of communication. When people with ID are struggling to communicate, they often will give up and choose to be quiet. Touchscreen device communication technologies can provide some people with ID confidence that they do not have to rely on verbal communication [8]. Some individuals with ID will be able to use touchscreen devices as part of their everyday communication systems. There is alternative/augmentative communication (AAC) software that has been developed specifically for touchscreen devices, and that facilitates the communication experience of individuals with disabilities. Proloquo2go is an app that has been shown to be effective in increasing communication for students with disabilities [29]. There are currently thousands of students who struggle to communicate verbally who use touchscreen devices as their primary method of communication.

Further analyzing the concept of adding meaning to daily experiences, Hilary Putnam said that “( ... ) meaning just isn't in the head" [30]. This can be understood as "meaning" that emerges through communication exchanges between people. Touchscreen devices are then a mediating part of the communication process. We can, for example, say (as an extension of the last example), "Can you show us the yoga Sun Salutation Pose?" She can reply, "You too?" (would you like to join?). Through the help of the video preserved on the touchscreen device, we are now entering a complex communication process about an instance that firstly took place at school and now is igniting joint action. This might never have become possible without the help of the touchscreen device. Touchscreen devices allow people with ID to expand their cognitive, emotional and social capabilities, giving them a way to expand meaning.

\subsubsection{Capturing Memories}

Some people with ID can take pictures and videos with their touchscreen devices. This allows them to capture moments to remember later. In other cases, the people assisting those with ID can do this for them. Enabling and utilizing this technology makes it possible for people with ID to communicate and expand on their experiences and memories using pictures and videos [31]. When prompted with questions, people with ID might be able to independently locate the media on their 
touchscreen and proudly express what they have been doing, their interests, and so forth. In this way, people with ID are able to expand and elaborate their communication by saving pictures and videos, and thus people with ID can expand the possibilities for reflecting and remembering. The touchscreen device can be a leisure activity, or by inviting others to join, the touchscreen device can facilitate a social joint activity. It can be a daunting task to communicate a day at the beach to your friends if they did not attend and if you have very few words to do it with. A couple of short videos, some pictures and some strategic show and tell questions can help bring the day at the beach alive as a shared experience. The fifth author, for example, sometimes takes the initiative to watch videos from last year's summer holiday to reflect and communicate the excitement for the upcoming summer holiday. She is then not only remembering and taking an initiative to build her own expectations, but she can then be the initiator of building expectation for those around her. A person with ID is most often on the receiving end of help and initiative. It makes a radical change to be the instigator.

\subsection{Touchscreen Devices as a Tool for Learning Digital Skills}

Another benefit to touchscreen devices is their ability to deliver high-quality instruction and intuitively manageable interface in an engaging manner. For a device to be utilized to its maximum possibilities, it needs to be both interesting and manageable. A touchscreen device is not only portable, but it also does not require the assistance of a keyboard. Many individuals with ID struggle with the fine motor skills or/and the letter and number competence necessary to operate a keyboard and mouse. This makes the use of traditional computers difficult [32]. Some people with ID will also need immediate, and positive, reinforcement from the device they are using, or they will become disengaged with it regardless of the content.

Touchscreen devices have been used to teach individuals with ID a wide variety of skills. They have been used to teach vocational, social, functional and academic skills [33-35]. There is a wide body of research depicting AT, including tablets, smartphones and other touchscreen devices, as effective means of providing instruction for a wide range of skills to individuals with ID $[1,8,18]$.

There are many apps that are not dependent on reading and/or writing skills which can be very motivating for not only entertainment purposes but also for developing digital skills.

An example of this is maybe starting with a basic puzzle app (puzzles only containing five or fewer pieces) - reinforced with a pleasant soft sound when the pieces are put in the right place. After practicing, understanding is developed and digital skills are learned, which can then lead to independently turning on the touchscreen device and locating the app.

After a period of motivating, positively reinforcing sessions, more challenging apps might be needed for the further building of digital skills. Some apps can provide hours of play and exploration. Many apps are also interactive, cause and effect type apps. The complexity is amazing. People with limited verbal and language skills can communicate and interact with the assistance of touchscreen devices. Quality apps without reading or writing requirements are abundant, highly motivating, and self-reinforcing. An example could be the app My PlayHome (https://apps.apple.com/us/app/myplayhome/id439628153). In this app the user can make digital dolls perform most everyday life tasks and situations in the home, in stores, in the hospital and in school. The app is structured in a way that give possibilities for creating your own events through interacting with a vast body of everyday things and environments. It can all be done without the use of letters or numbers. It is educational and like real life, and it enhances motor skills while having fun. Through apps like this, we argue that people with ID can develop precise and relevant hand actions for touchscreen control.

Accessibility is a major benefit to using touchscreen devices for people with ID. By following the flow of interest and passions, people with ID can develop skills to use touchscreen devices with intent and direction. An app like YouTube can even be used as an alternative search engine when ordinary search engines like Safari, Google, Firefox, Chrome, etc., are out of reach for those who cannot read, write or use voice assisted strategies [4]. We refer to this article for a deeper understanding of how this 
can be possible. In our experience, YouTube can allow the opportunity to access the internet and create some degree of systematic search opportunities [36].

\subsection{Touchscreen Devices as a Means of Inclusion and Communication}

Finally, a benefit to using touchscreen devices is that they enable participation in communication. Letters and emails are not ideal for people with ID who also have limited reading, writing and verbal language skills. This means there is always a lot of communication going on which they might be excluded from. What if teachers, therapists, parents, peers, and so on, were challenged to use video instead of written letters and messages? Most relevant touchscreen devices also have video messaging and video calling capabilities. We promote the idea that communication can be understood as "doing together" as much as "talking together". Our fifth author talks on video phone (Messenger) from 30 minutes up to two hours a day with family and friends. A five-minute phone call for a person that is only able to express a limited amount of words and sentences can be very depressing. An alternative is "doing and talking". For example, she can be doing arts and crafts at her end of the video conversation with someone like grandma, who is making dinner at the other end. They can be doing, showing and talking together. This is a very hands-on approach to communication. It gives the person with ID a very direct communication possibility that is less dependent on word and sentence skills. Because our society primarily relies on verbal communication, this can cause significant stress for those with ID, and exclude them from social interaction. Fortunately, our research shows the possibility that touchscreen devices can be utilized as an effective means of enhancing communication for individuals with ID [29].

\section{Conclusions}

Touchscreen devices have become increasingly popular for their modern conveniences in the context of everyday life, such as internet access and social networking. Touchscreen devices can open up a world of new possibilities for people with ID_changing the way they see, hear and interact with the world. Touchscreen devices leverage universal design principles, which can assist in communication, access, navigation and independence. Our research and development work are in many ways pioneering work. The methodology of having a co-researcher with a severe intellectual disability showing the way is giving us perspectives we have just begun to understand. We argue that in our special case, more than $6000 \mathrm{~h}$ of play and use of an ordinary touchscreen device can develop skills. Some of these skills are already being used to enhance the social life of the individual they concerns. Some of these skills show promise for more practical applications in the future. At the same time, we are seeing that an average touchscreen device, using ordinary generic apps, is showing great universal design potential. In this article we are sharing some of this emerging promise, and showing that the people it concerns - the people with ID — can take an active part in research and development. Inclusion, collaboration, participation and active citizenship are all practically possible, fruitful and beneficial [37]. Further research is needed to fully understand the true potential of touchscreen devices for individuals with ID.

Hehir [23] writes: "( . . ) disability is a natural form of human diversity that is neither pitiable nor heroic, that disability is only tragic when the needs of disabled people are not met".

Author Contributions: Conceptualization K.S.K., R.O.K., A.K.A. and S.D.K., writing original draft K.S.K., R.O.K., A.-R.K.A., and H.C.B. writing review and editing K.S.K., R.O.K., H.C.B. and A.-R.K.A. All authors have made substantial contributions to the article and have agreed to the published version of the manuscript.

Funding: This research received no external funding.

Conflicts of Interest: The authors declare no conflict of interest. 


\section{References}

1. Williams, P.; Shekhar, S. People with learning disabilities and smartphones: Testing the usability of a touchscreen interface. Educ. Sci. 2019, 9, 263. [CrossRef]

2. Kversøy, K.S.; Kversøy, S.D. Exploring career possibilities for people with intellectual disabilities. Ind. J. Career Livelihood Plann. 2018, 1, 39-47.

3. Kostakopoulou, D. Co-creating European Union citizenship: Institutional process and crescive norms. Camb. Yearb. Eur. Legal Stud. 2013, 15, 255-282. [CrossRef]

4. Kversøy, K.S.; Alhassan, A.-R.K.; Kversøy, E.D.; Kversøy, S.D. How can People with Intellectual Disabilities use YouTube as an Alternative Search Engine on the Internet? Ind. J. Career Livelihood Plann. 2019, 1, 45-49.

5. The Norwegian National Research Ethics Committees (NENT). Guidelines for Research Ethics in the Social Sciences, Humanities, Law and Theology. 2016. Available online: https:/www.etikkom.no/globalassets/ documents/english-publications/60126_fek_guidelines_nent_digital.pdf (accessed on 5 July 2020).

6. Vygotsky, L.S. Mind in society. In The Development of Higher Psychological Processes; Harvard University Press: Cambridge, MA, USA, 1978.

7. Hoppestad, B.S. Current perspective regarding adults with intellectual and developmental disabilities accessing computer technology. Disabil. Rehabil. Assist. Technol. 2013, 8, 190-194. [CrossRef] [PubMed]

8. Kagohara, D.M.; van der Meer, L.; Ramdoss, S.; O’Reilly, M.F.; Lancioni, G.E.; Davis, T.N.; Green, V.A. Using iPods ${ }^{\circledR}$ and iPads ${ }^{\circledR}$ in teaching programs for individuals with developmental disabilities: A systematic review. Res. Dev. Disabil. 2013, 34, 147-156. [CrossRef] [PubMed]

9. Wehmeyer, M.L.; Palmer, S.B.; Smith, S.J.; Davies, D.K.; Stock, S. The efficacy of technology use by people with intellectual disability: A single-subject design meta-analysis. J. Spec. Educ. Technol. 2008, 23, 21-30. [CrossRef]

10. Motti, L.G.; Vigouroux, N.; Gorce, P. Interaction techniques for older adults using touchscreen devices: A literature review. In Proceedings of the 25th Conference on l'Interaction Homme-Machine, Talence, France, 12-15 November 2013; pp. 125-134.

11. Hegarty, J.R.; Aspinall, A. The use of personal computers with adults who have developmental disability: Outcomes of an organisation-wide initiative. Br. J. Dev. Disabil. 2006, 52, 137-154. [CrossRef]

12. Jerome, J.; Frantino, E.P.; Sturmey, P. The effects of errorless learning and backward chaining on the acquisition of internet skills in adults with developmental disabilities. J. Appl. Behav. Anal. 2007, 40, 185-189. [CrossRef]

13. Gray, T.; Silver-Pacuilla, H.; Brann, A.; Overton, C.; Reynolds, R. Converging trends in educational and assistive technology. In Breakthrough Teaching and Learning; Springer: New York, NY, USA, 2011; pp. 5-24.

14. Assistive Technology Act; 29 U.S.C. § 3; U.S. Government Printing Office: Washington, DC, USA, 2004.

15. Individuals with Disabilities Education Improvement Act; H.R. 1350, 108th Congress; U.S. Government Printing Office: Washington, DC, USA, 2004.

16. Koch, K. Stay in the Box! Embedded assistive technology improves access for students with disabilities. Educ. Sci. 2017, 7, 82. [CrossRef]

17. Edyburn, D.L. Assistive technology and students with mild disabilities. Focus Except. Child. 2000, 32. [CrossRef]

18. Cook, A.M.; Polgar, J.M. Cook's and Hussey's Assistive Technologies: Principles and Practice; Mosby Elsevier: St. Louis, MO, USA, 2007.

19. Perlman, L.G. The Views of Consumers with Learning Disabilities, Mental Retardation and Their Caregivers; JSTOR: New York, NY, USA, 1993.

20. Brown, R. Adult education and intellectual and allied developmental disabilities. In International Encyclopedia of Rehabilitation; CIRRIE: New York, NY, USA, 2010.

21. Vanderheiden, G.C. Application Software Design Guidelines: Increasing the Accessibility of Application Software to People with Disabilities and Older Users. 1999. Available online: http://trace.wisc.edu/docs/ software_guidelines/toc.htm (accessed on 5 July 2020).

22. Vanderheiden, G.C. Universal design and assistive technology in communication and information technologies: Alternatives or complements? Assist. Technol. 1998, 10, 29-36. [CrossRef] [PubMed]

23. Hehir, T. New Directions in Special Education. Eliminating Ableism in Policy and Practice; Harvard Education Press: Cambridge, MA, USA, 2005.

24. Martin, G.E.; Ausderau, K.K.; Raspa, M.; Bishop, E.; Mallya, U.; Bailey, D.B., Jr. Therapy service use among individuals with fragile $\mathrm{X}$ syndrome: Findings from a US parent survey. J. Intell. Disabil. Res. 2013, 57, 837-849. [CrossRef] [PubMed] 
25. Peterson-Karlan, G.R.; Parette, H.P. Integrating assistive technology into the curriculum. In Research—Based Practices in Developmental Disabilities; Prette, H.P., Peterson-Karlan, G.R., Eds.; SAGE Publications: Los Angeles, CA, USA, 2008; pp. 183-214.

26. Putnam, H. Meaning and reference. In The Philosophy of Language; Martinich, A.P., Ed.; Oxford University Press: Oxford, UK, 1973; pp. 308-315.

27. Davidson, D. Subjective, Intersubjective, Objective; Claredon Press: Oxford, UK, 2001.

28. Gadamer, H.-G. Truth and Method; Sheed and Ward: London, UK, 1989.

29. Bloh, C.; Johnson, N.; Strohl, C.; Tidmarsh, N. Increasing communication for students with visual impairments and developmental disabilities. In The Analysis of Verbal Behavior; Springer: New York, NY, USA, 2020; pp. 1-12.

30. Humphrey, N. Consciousness: Knowing the unknowable. Soc. Res. 2020, 87, 157.

31. Edrisinha, C.; O’Reilly, M.F.; Choi, H.Y.; Sigafoos, J.; Lancioni, G.E. "Say Cheese": Teaching photography skills to adults with developmental disabilities. Res. Dev. Disabil. 2011, 32, 636-642. [CrossRef] [PubMed]

32. Rintala, P.; Loovis, E.M. Measuring motor skills in Finnish children with intellectual disabilities. Percept. Mot. Ski. 2013, 116, 294-303. [CrossRef] [PubMed]

33. Kellems, R.O.; Cacciatore, G.; Osborne, K. Using an augmented reality-based teaching strategy to teach mathematics to secondary students with disabilities. Career Dev. Trans. Except. Individ. 2019. [CrossRef]

34. Kellems, R.O.; Morningstar, M.E. Using video modeling delivered through iPods to teach vocational tasks to young adults with autism spectrum disorders. Career Dev. Trans. Except. Individ. 2012, 35, 155-167. [CrossRef]

35. Kellems, R.O.; Rickard, T.H.; Okray, D.A.; Sauer-Sagiv, L.; Washburn, B. iPad ${ }^{\circledR}$ video prompting to teach young adults with disabilities independent living skills: A maintenance study. Career Dev. Trans. Except. Individ. 2017, 41, 175-184. [CrossRef]

36. Bayor, A.; Bircanin, F.; Sitbon, L.; Ploderer, B.; Koplick, S.; Brereton, M. Characterizing participation across social media sites amongst young adults with intellectual disability. In Proceedings of the 30th Australian Conference on Computer-Human Interaction, Melbourne, VIC, Australia, 4-7 December 2018; pp. 113-122.

37. Kversøy, K.S. Relevant forskning for hvem? Relevans for dem forskningen involverer gjennom utvidede muligheter for medvirkning. Forsk. Forand. 2018, 1, 91-109. [CrossRef]

(C) 2020 by the authors. Licensee MDPI, Basel, Switzerland. This article is an open access article distributed under the terms and conditions of the Creative Commons Attribution (CC BY) license (http://creativecommons.org/licenses/by/4.0/). 